\title{
BMJ Open Development of the Prevent for Work questionnaire (P4Wq) for assessment of musculoskeletal risk in the workplace: part 1-literature review and domains selection
}

\author{
Francesco Langella (D) , ${ }^{1}$ Steffan Wittrup McPhee Christensen, ${ }^{2,3}$ \\ Thorvaldur Skuli Palsson (10 , ${ }^{2}$ Morten Høgh, ${ }^{2}$ Nicolo Gagni, ${ }^{1}$ \\ Pablo Bellosta-López (10 , ${ }^{4}$ David Høyrup Christiansen, ${ }^{5,6}$ Mauro Delle Chiaie, ${ }^{1}$ \\ Victor Domenéch-García, ${ }^{4}$ Venerina Johnston, ${ }^{7}$ Grace P Y Szeto, ${ }^{8}$ \\ Jorge Hugo Villafañe (D), ${ }^{9}$ Pablo Herrero (D) , ${ }^{10}$ Pedro Berjano ${ }^{1}$
}

To cite: Langella $\mathrm{F}$, Christensen SWMcP, Palsson TS, et al. Development of the Prevent for Work questionnaire (P4Wq) for assessment of musculoskeletal risk in the workplace: part 1-literature review and domains selection. BMJ Open 2021;11:e043800. doi:10.1136/ bmjopen-2020-043800

- Prepublication history for this paper is available online. To view these files, please visit the journal online (http://dx.doi. org/10.1136/bmjopen-2020043800).

Received 17 August 2020 Revised 04 March 2021 Accepted 29 March 2021

D) Check for updates

(c) Author(s) (or their employer(s)) 2021. Re-use permitted under CC BY-NC. No commercial re-use. See rights and permissions. Published by BMJ.

For numbered affiliations see end of article.

\section{Correspondence to} Dr Francesco Langella; francesco.langella.md@gmail. com

\section{ABSTRACT}

Objective This study aims to define appropriate domains and items for the development of a self-administered questionnaire to assess the risk of developing workrelated musculoskeletal disorder (WMSD) and the risk of its progression to chronicity.

Design Literature review and survey study.

Setting and participants A literature review and a two-round interview with 15 experts in musculoskeletal pain were performed to identify the available domains for WMSD assessment.

Interventions and outcome To ensure quality, only validated questionnaires were included for the Delphi process. A three-round Delphi method, with three round steps, was used to select the most pertinent and relevant domains and items.

Results Nine questionnaires were identified through the expert discussion and literature review, comprising 38 candidate domains and 504 items. In the first round of the Delphi group, 17 domains reached more than $70 \%$ agreement and were selected. In the second round, 10 domains were rejected, while 11 were selected to complete the pool of domains. In the third and final round, 89 items belonging to 28 domains were defined as significant to develop a WMSDs risk assessment questionnaire.

Conclusions No specific risk assessment questionnaires for WMSDs were identified from the literature. WMSD risk of presence and chronicity can be defined by an assessment tool based on the biopsychosocial model and the fear-avoidance components of chronic pain. The present study provides the formulation and operationalisation of the constructs in domains and items needed for developing and validating the questionnaire.

\section{INTRODUCTION}

Work-related musculoskeletal disorders (WMSD) have been defined as 'disorders of the muscles, nerves, tendons, joints, cartilage
Strengths and limitations of this study

Based on the Delphi method with experts, the theory of the biopsychosocial nature of musculoskeletal problems and the fear-avoidance model of chronic pain provided a solid conceptual framework for the questionnaire development to assess the risk of work-related musculoskeletal disorder (WMSD).

- The Delphi panel included experts with different research and professional backgrounds: medical doctors, physical therapists, statistical methodologists, engineers of the 'prevention and protection service', and psychologists.

- The panel of experts is not homogeneously constructed, physiotherapists were over-represented and some figures were not involved as stakeholders, members of the compensation system and workers.

- The study aimed to collect an extensive array of domains including psychosocial, physical and fearavoidance components of pain to reduce the risk of underestimation of WMSD predictors.

- This study operationalises the risk of WMSDs into domains and items that will permit the development and validation of the questionnaire for WMSDs.

and spinal discs associated with exposure to risk factors in the workplace'. ${ }^{1}$ The European Agency for Safety and Health at Work reported in 2019 that three out of five workers suffer from musculoskeletal disorders, most commonly of the back and upper limb. ${ }^{2}$ Furthermore, $60 \%$ of workers with a workrelated health problem identified musculoskeletal disorders as the most serious ones. ${ }^{2}$ It might be assumed that workers exposed to substantial physical stressors are at higher risk of being significantly more bothered by musculoskeletal pain. The sixth European 
Working Conditions Survey showed that the prevalence of WMSD ranged from $49 \%$ to $69 \%$ and affected all the work activity categories. ${ }^{2}$ As for most other painful conditions, women experience a slightly higher prevalence than men. ${ }^{2}$ Prevalence of WMSD increases with age and workers with the lowest levels of education are more likely to report muscular pain as well as develop chronic symptoms. ${ }^{2}$

Musculoskeletal problems introduce a substantial burden on society and individuals. ${ }^{3}$ In 2016, musculoskeletal issues caused a loss in production equal to $€ 17.2$ billion in Germany alone translating to 30.4 billion in loss of gross value. ${ }^{4}$ Data from the USA show that WMSDs accounted for the largest proportion of workers' compensation claims and at least one-third of the loss of labour time. ${ }^{5}$ The 2020 report of the European Agency for Safety and Health at Work shows that musculoskeletal conditions are the second most prevalent cause of loss of disability-adjusted life years (DALY) (16\% overall), only surpassed by cancer $(25 \%)$. Individuals reporting musculoskeletal conditions have decreased health-related quality of life (HRQoL), including both its physical and the mental dimensions. ${ }^{6}$

Although it is not always possible to identify when musculoskeletal disorders are caused by workplace-related factors, differences in prevalence have been identified between workers and nonworkers. Pain is a complex and multifactorial event. Nevertheless, Jackson et al reported that the prevalence of chronic low back pain was 2.5 times higher in working than in nonworking populations, suggesting that work-related factors may contribute to the pain problem. ${ }^{7}$

The prevalence and impact of WMSDs on DALY, HRQoL as well as the economic burden justify preventive strategies. Evidence suggests that WMSDs causes are multifactorial and preventative strategies may be effective. ${ }^{4}$ A study from 2014 demonstrated lower prevalence rates of WMSDs in countries that had implemented preventative strategies and that large companies were more likely to provide prevention activities than small ones. ${ }^{8}$ As WMSDs are multifactorial in nature, prevention should address multiple factors, such as exposure to physical, psychosocial and organisational risks. Furthermore, to increase the efficiency of preventive actions, individuals at higher risk should be identified and targeted. Although not widely used so far, information technology (IT) allows for targeting not only companies or groups of workers but also individuals, directly via resources made available through personal devices, but this approach is not widely used.

Previous literature suggests that clinical and nonclinical interventions can effectively reduce absenteeism and the disability related to WMSDs. ${ }^{9}$ In particular, a multidisciplinary approach seems the cornerstone to collect good outcomes. ${ }^{10}$ An early diagnostic assessment, psychosocial interventions (eg, multifaceted interventions with education and training sessions with experts to discuss topics related to workplace mental health and social marketing campaign), ${ }^{11}$ workplace factors management (eg, workplace barrier removal, safety at work, management of aversive workplace factors and promotion of appetitive factors $)^{12}$ and providing educational contents on musculoskeletal pain ${ }^{3}$ have shown effective to reduce the incidence of WMSDs and absenteeism related to it.

The present study is a part of the 'Prevent for Work' (P4W) Project, funded by the European Commission in the framework of the Erasmus+programme. It is an initiative to increase the awareness, collect and make available high-quality evidence in the field, develop and make available educational content and courses for professionals and the general population to prevent the occurrence of WMSDs. One of the milestones of the project included the development of a questionnaire (the $\mathrm{P} 4 \mathrm{Wq}$ ) to detect factors related to the development of WMSDs and, thus, to identify individuals at risk in order to target these individuals for prevention efforts.

This study describes the first phase of development of a self-administered questionnaire $(\mathrm{P} 4 \mathrm{Wq})$ to assess the risk of developing WMSDs and the risk of WMSD evolution into chronicity. The questionnaire is intended not only to be used in clinical studies, occupational studies but also to orientate individuals regarding their degree of risk as a first step to deliver preventive actions, including those that can be provided through personal IT devices.

The study aims to define appropriate domains and items for risk factors of nontraumatic WMSDs to make them available to create a risk assessment questionnaire for adult working population.

\section{METHODS}

\section{Design}

This study uses a Delphi group method ${ }^{13} 14$ to identify the domains and items to be included in the questionnaire. The questionnaire is conceived as self-administered, applicable to the general adult working population, to include physical, psychological and social aspects of risk, to be short (less than 25 questions) and administrable through an IT solution on a mobile device.

The study design was agreed on by the research group over two formal consensus meetings regarding which factors should be incorporated into the domains construct. It should provide a high ability to capture the risk of developing WMSDs and eventually the risk developing persistent symptoms. The first round was conducted online, but the second round was held faceto-face in November 2019 to summarise and gain a final consensus. After the discussions, notes were summarised to reflect the conclusions.

\section{Field of application}

For the purpose of this study research, wounds, sprains, thermal lesions, fractures or WMSD caused by slips, sprains, blunt trauma, vehicle accidents or similar, falls, electricity, biological contamination or radiation were not included. The questionnaire should (1) identify subjects 
at risk of developing WMSDs and (2) identify the subset of subjects at risk of WDMS evolution into chronicity.

\section{Creation of initial domain and item library}

After the second round of discussion, three researchers (NG, FL and PeBe) performed a systematic search of the literature to identify validated self-administered questionnaires to assess work conditions, musculoskeletal problems and work-related musculoskeletal conditions. Furthermore, the literature review aimed to reveal previous questionnaire based on a biological and psychosocial approach. The databases MEDLINE, CINAHL, EMBASE, Cochrane Register, OTseeker and ScienceDirect were searched for articles in any language from their inception to January 2020. The first group of terms included musculoskeletal pain, myalgia, neck pain, back pain, work-related muscle pain, shoulder pain, musculoskeletal pain, discomfort, injury, stress, fatigue, pain, disorder, syndrome, strain, cumulative trauma, cumulative trauma disorders, overuse, workload, neuropathic pain, disability, exposure, discomfort, symptoms, rupture, damage, depression, neuralgia, injuries, tendinitis, multiple trauma, neuropathy, overuse syndrome, joint, cartilage, distress, damage, weakness, illness, trauma, disability, diseases, pain, symptom, dysfunction. The second group of terms included questionnaire, survey, self-assessment, form, aetiology, diagnosis, evaluation, exposition, high risk, risk, incidence, perception, prediction, prevention, prognosis, prospective, retrospective, observational, factor, assessment, scoring, system, algorithm, self-report, survey, questionnaires, tool, instrument, threshold, primary prevention, screening, detection, secondary prevention, scale, rating, epidemiology, control, measurement, surveillance, hazard, model, absenteeism, return to work, sick leave, self-report, sickness absence, physiopathology, pilot projects, cost-benefit analysis, quality of life. The identified questionnaires were summarised and a list of potential domains for the 'P4Wq' questionnaire was created. Additionally, a list of items was generated to reflect how previous selfadministered questionnaires had operationalised the included domains.

\section{Delphi group}

A Delphi group of experts in the field of WMSDs was formed, including the members of the research team and external experts on invitation. ${ }^{15}$ The group was composed of 15 participants with different backgrounds and expertise, including ten physiotherapists $(\mathrm{PH}, \mathrm{PBL}$, VD-G, MH, TSP, DC, SWMC, VJ, GPYS, MH), two orthopaedic surgeons (PeBe and FL) one psychologist (SJL), one engineer (MDC) and one research methodologist (JHV).

The Delphi panel was given two tasks, first to rank the identified domains according to relevance and to select those items considered most relevant for each of these domains. ${ }^{16}$

A total of three electronic surveys were conducted. The results at the end of each round were summarised before the next round, thereby reducing the number of items the expert panel was asked to review and rate for relevance.

- In the first round, the experts received an electronic survey including all the domains identified in the literature search. They indicated their preference for inclusion of each of the identified domains. The relevance of each domain was ranked on a 5-point Likert scale (1-strongly disagree to include this domain; 2-disagree to include this domain; 3-neither agree or disagree to include this domain; 4-agree to include this domain and 5-strongly agree to include this domain). For each domain, three related questions were presented to describe its content and its relevance better. The responses were aggregated into two categories ( 1 to 3 into 'not include' and 4 to 5 into 'include'). According to previous studies, ${ }^{16} 17$ all the domains that received $70 \%$ or higher agreement as 'include' were included. Similarly, domains rated as 'not include' by $70 \%$ or more were rejected. All experts had the chance to provide comments and suggestions for each domain and proposals for additional domains that were deemed necessary and not currently represented in the list of domains and items.

- In the second round, domains with an 'include' agreement between $50 \%$ and $70 \%$ were submitted again. The participants could choose to 'include this domain' or 'reject this domain'. After this round, domains with an agreement of $70 \%$ or higher as 'include' were included along with the results of round 1.

- In the third round, the Delphi panel received an electronic survey containing all the included domains. For each domain, all the items related were presented. The expert panel was asked to rank the items from most relevant to least relevant. After summarising all the answers, the three most relevant items from each domain were included in the final item pool.

Finally, three researchers (NG, FL, PeBe) summarised the results, analysed the item pool, the expert suggestions and the rejected items in order to evaluate whether relevant items were lost and eventually included those relevant items in the final pool. A flowchart of the process, including the Delphi panel, is seen in figure 1. The study was conducted in accordance with Standards for QUality Improvement Reporting Excellence SQUIRE V.2.0 guidelines. ${ }^{18}$

\section{Patient and public involvement}

For this study, patients' priorities, experience and preferences were not involved in the design of the study, forming the aims, statistical strategies or data syntheses. Study findings will be disseminated on a publicly available platform (websites and on social media).

\section{RESULTS}

The preliminary literature research failed to identify a questionnaire suitable for the purpose and use of our initiative, with the characteristics of being short, 
Figure 1. Descriptive Workflow.
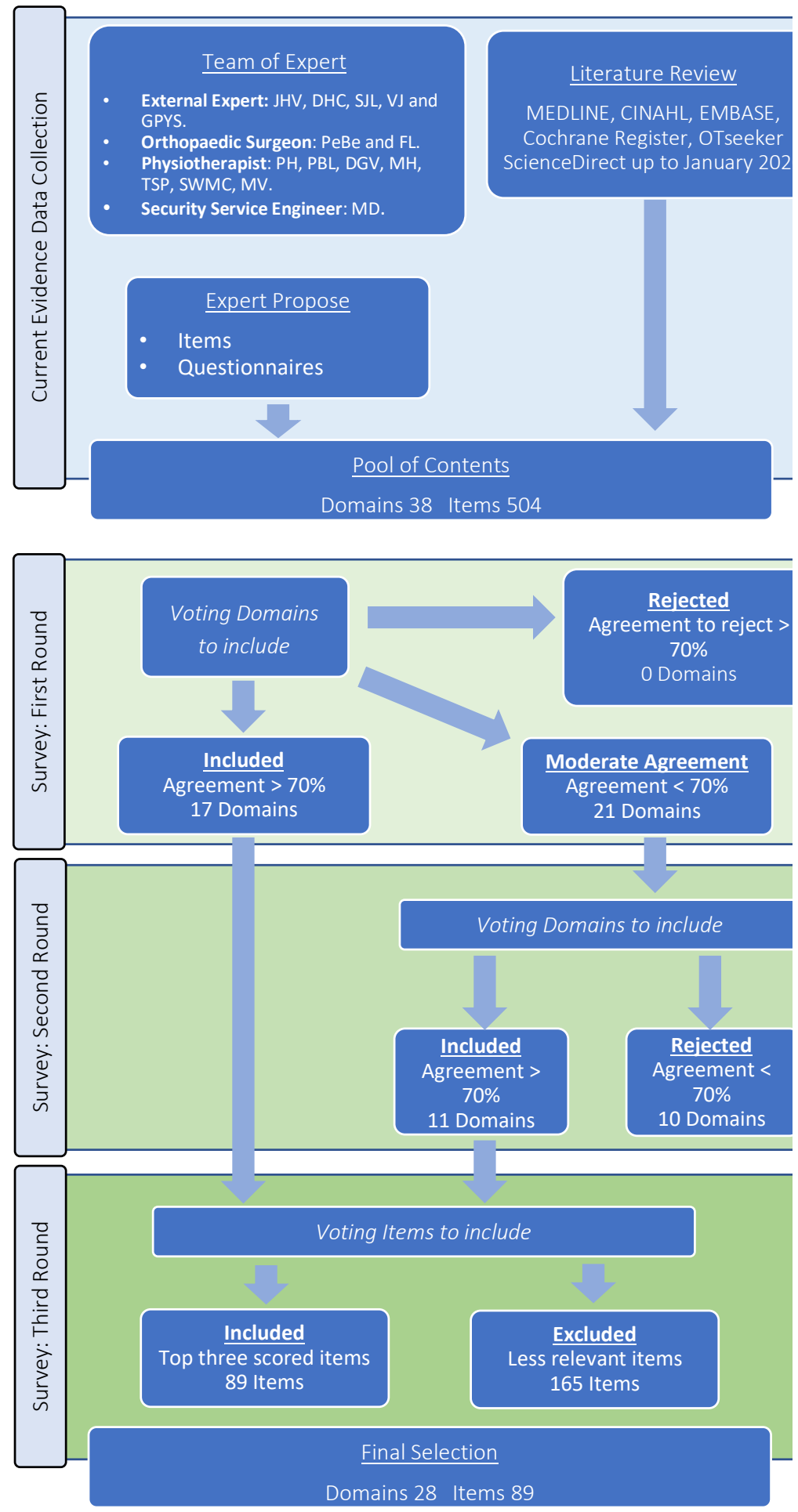

Figure 1 Flowchart of the steps of the Delphi process. DHC, David Høyrup; DGV, Doménech García; Víctor, Christiansen; FL, Francesco Langella; GPYS, Grace P Y, Szeto; SJL, Steven J, Linton; JHV, Jorge Hugo Villafañe; MV, Morten Villumsen, MH, Morten, Høgh; PeBe, Pedro, Berjano; PH, Pablo, Herrero; PBL, Pablo, Bellosta-Lopez; SWMC, Steffan Wittrup McPhee, Christensen; VJ, Venerina, Johnston; TSP, Thorvaldur Skuli, Palsson; MD, Mauro, Delle Chiaie. 
self-administered, multidomain, aiming to assess the risk of presenting WMSDs and their evolution into chronicity. For this reason, the development and validation of a new assessment tool remain pertinent.

According to the previous researches, ${ }^{19-21}$ heavy physical work, high psychosocial work demands and the presence of comorbidities were risk factors that had at least reasonable evidence for the development of WMSDs. Smoking and body mass index were considered risk factors too. Regarding mechanical factors, they found that the most frequently reported ones with reasonable evidence were excessive repetition, awkward postures and heavy lifting.

The literature review showed how both mechanical demands at work as well as personal and psychosocial factors, contribute to new incidence of WMSDs (though with variable distribution depending on the kind and anatomical region involved).

A systematic review of longitudinal studies by Kraatz et $a l^{22}$ found 'evidence for an incremental effect of different psychosocial work factors (in addition to the effect of physical job factors)' for the presentation of neck and shoulder disorders. The contribution of psychological risk factors to the development of WMSDs and their chronicity have been identified by previous authors. ${ }^{23}$

These data from longitudinal studies suggest that the phenomenon of WMSDs is better interpreted using the biopsychosocial model ${ }^{24}$ as a framework. This model assumes that both biological and psychosocial causes (and their interaction) explain better than a simplified model the clinical presentation of the symptoms. According to previous researches,${ }^{25-27}$ the development and chronicity of WMSDs are influenced by physical activities and/or working postures and working conditions in the workplace. Additionally, the risk of chronicity of musculoskeletal conditions (which is an important determinant of the social and economic burden caused by WMSDs) has shown to be well predicted by models that incorporate the fear-avoidance component of pain. ${ }^{28}$ However, fear-avoidance is probably not the only factor influencing disability and chronicity. This study has provided a large array of domains including both psychosocial and physical factors in order to reduce the risk of underestimation of predictors of WMSD. The modulation of intensity and evolution into chronicity of pain are explained by the result of interactions between the pain sensation and patient's emotional elaboration, leading to fear, avoidance, disuse and disability, decreasing the threshold of pain. This further supports the need to adapt our conceptual framework and measurement tool to both physical and psychosocial aspects of the individual experience.

The result of the consensus meetings what that traits predisposing to WMSD risk can be measured by two groups of factors: (1) physical factors, including perceived mechanical loads, physical or postural effort requirements at the workplace and ergonomics and (2) psychosocial factors, including psychological well-being at the workplace, known psychosocial predictors of back, musculoskeletal pain presentation, chronicity and selfperceived health.

The research group considered that physical factors can be measured by a combination of the following candidate domains, which have been previously described in the literature on musculoskeletal pain and WMSDs: force exertion, ${ }^{29}$ dynamic loads, ${ }^{29}$ static loads,${ }^{29}$ repetitive loads,${ }^{29}$ ergonomic environment, ${ }^{29}$ worker physical condition. ${ }^{30}$

Similarly, the psychosocial factors can be measured by a combination of the following previously described domains: quantitative work demands, ${ }^{29}$ cognitive work demands, ${ }^{31}{ }^{32}$ demands for hiding emotions at work, ${ }^{31}$ sensory work demands, ${ }^{31}$ influence at work, ${ }^{31}$ possibilities for development at work, ${ }^{31}$ degree of freedom at work, ${ }^{31}{ }^{33}$ commitment to the workplace, ${ }^{31}{ }^{32} 34$ predictability, ${ }^{31}$ role clarity at work, ${ }^{31}{ }^{32}$ role conflicts at work, ${ }^{31}{ }^{32}$ quality of leadership at work, ${ }^{31}{ }^{32}$ social support at work, ${ }^{31-33}$ feedback at work, ${ }^{31}$ social relations at work, ${ }^{31} 32$ sense of community at work, ${ }^{31}$ insecurity at work, ${ }^{31} 33$ job satisfaction, ${ }^{31}$ general health, ${ }^{31}$ mental health, ${ }^{31}$ vitality, ${ }^{31}$ behavioural stress, ${ }^{31}$ somatic stress, ${ }^{31}$ cognitive stress, ${ }^{31}$ sense of coherence, ${ }^{31}$ problem-focused coping, ${ }^{31}$ selective coping, ${ }^{31}$ resignation coping, ${ }^{31}$ kinesiophobia, ${ }^{35}$ pain catastrophising. ${ }^{36}$

To select the most appropriate domains and items, a discussion and selection process was conducted by the Delphi panel. Confirmation of the research hypothesis will later be tested in a validation process, which will be the scope of a different study.

\section{Domain and item selection}

Nine questionnaires were identified from the literature search and group feedback. After elimination of repeated domains and items, a database of 38 potential domains (table 1) with 504 corresponding items was constructed. Questionnaires assessing the identified domains are displayed in table 2.

In the first round with the Delphi panel, 17 candidate domains reached more than $70 \%$ agreement and were selected. No candidate domains had $70 \%$ or higher agreement to reject and no domain was, therefore, rejected in round 1 . The remaining 21 candidate domains were moved to a second round in the Delphi process. In the second round, 11 candidate domains gained $70 \%$ or higher agreement and were added to the pool. In the third round, 89 items belonging to 28 domains were selected and moved to the next phase. Table 3 details how the physical and psychosocial components of the Patient Reported Outcome Measures (PROMs) construct are operationalised into measurable items.

\section{DISCUSSION}

WMSDs are complex conditions that can directly impact DALY and HRQoL as well as being a substantial socioeconomic burden. This study aimed at identifying the necessary domains for assessing WMSDs. The study findings indicate that 28 domains covering two factors are required to permit the development of a questionnaire WMSD risk assessment. Prevention has shown to be effective in 
Table 1 Initial pool domains

\section{D} number Domains

\begin{tabular}{|c|c|c|}
\hline number & Domains & Questionnaire \\
\hline 1 & Quantitative work demands & COPSOQ \\
\hline 2 & Cognitive work demands & COPSOQ; ERI; QPS - N \\
\hline 3 & Demands for hiding emotions at work & COPSOQ \\
\hline 4 & Sensory work demands & COPSOQ \\
\hline 5 & Influence at work & COPSOQ \\
\hline 6 & $\begin{array}{l}\text { Possibilities for development at } \\
\text { work }\end{array}$ & COPSOQ \\
\hline
\end{tabular}

\begin{tabular}{|c|c|c|c|c|}
\hline 7 & Degree of freedom at work & COPSOQ; JCQ & $x$ & \\
\hline 8 & Meaning of work & COPSOQ & $\mathbf{x}$ & \\
\hline 9 & Commitment to the workplace & COPSOQ; ERI; N-QPS & & $x$ \\
\hline 11 & Role clarity at work & COPSOQ; QPS - N & & $x$ \\
\hline 12 & Role conflicts at work & $\begin{array}{l}\text { COPSOQ; QPS - N; } \\
\text { JCQ; }\end{array}$ & $\mathbf{x}$ & \\
\hline 14 & Social support at work & JCQ; COPSOQ & $\mathbf{X}$ & \\
\hline 15 & Feedback at work & COPSOQ & & $x$ \\
\hline 16 & Social relations at work & COPSOQ; QPS - N & $\mathbf{X}$ & \\
\hline 17 & Sense of community at work & COPSOQ & $x$ & \\
\hline
\end{tabular}

18 Insecurity at work COPSOQ; JCQ; ERI X

19 Job satisfaction COPSOQ; ERI, ÖMPQ $\mathbf{X}$

20 General health COPSOQ; NMQ; ÖMPQ $\mathbf{x}$

21 Mental health COPSOQ $\mathrm{x}$

22

23

24

25

26

$$
27
$$$$
28
$$$$
29
$$$$
30
$$$$
3
$$

\begin{tabular}{|c|c|c|c|c|}
\hline 32 & Force exertion & $\mathrm{DMQ}$ & & $\mathbf{x}$ \\
\hline 33 & Dynamic loads & $\mathrm{DMQ}$ & $x$ & \\
\hline 34 & Static loads & $\mathrm{DMQ}$ & $\mathbf{x}$ & \\
\hline 36 & Ergonomic environment & $\mathrm{DMQ}$ & & $\mathbf{x}$ \\
\hline 37 & Vibration & $\mathrm{DMQ}$ & & $x$ \\
\hline
\end{tabular}

The 28 domains selected have bold font.

Domains rejected have italic font.

COPSOQ, Copenhagen Psychosocial Questionnaire; DMQ, Dutch Musculoskeletal Questionnaire; ERI, Effort-Reward Imbalance; JCQ, Job Content Questionnaire; ÖMSQ, Örebro Questionnaire; NMQ, Nordic Musculoskeletal Questionnaire; PCS, Pain Catastrophising Scale; QPS-N, General Questionnaire for Psychological and Social Factors at Work (QPS-Nordic); TSK, Tampa Scale for Kinesiophobia. 
Table 2 Questionnaires extracted from the literature review

\begin{tabular}{|c|c|c|c|c|}
\hline $\begin{array}{l}\text { Name of the questionnaire } \\
\text { (acronym) }\end{array}$ & Paper titles & $\begin{array}{l}\text { Authors and year } \\
\text { of publication }\end{array}$ & Field of application & $\begin{array}{l}\text { Number of domains } \\
\text { (D) and items (I) }\end{array}$ \\
\hline $\begin{array}{l}\text { Nordic Musculoskeletal } \\
\text { Questionnaire (NMQ) }\end{array}$ & $\begin{array}{l}\text { Standardised Nordic } \\
\text { questionnaires for the analysis of } \\
\text { musculoskeletal symptoms }\end{array}$ & $\begin{array}{l}\text { Kuorinka I et al } \\
1987\end{array}$ & $\begin{array}{l}\text { Evaluation of } \\
\text { musculoskeletal symptoms } \\
\text { in an ergonomic or } \\
\text { occupational health context. }\end{array}$ & $D=3 I=42+18$ \\
\hline $\begin{array}{l}\text { Pain Catastrophising Scale } \\
\text { (PCS) }\end{array}$ & $\begin{array}{l}\text { The Pain Catastrophising Scale: } \\
\text { development and validation }\end{array}$ & $\begin{array}{l}\text { Sullivan M.J.L. et } \\
\text { al } 1995\end{array}$ & $\begin{array}{l}\text { Prediction of physical and } \\
\text { emotional distress in painful } \\
\text { stimulations. }\end{array}$ & $D=3 I=13$ \\
\hline $\begin{array}{l}\text { Örebro Questionnaire } \\
\text { (ÖMSQ) }\end{array}$ & $\begin{array}{l}\text { Can we screen for problematic } \\
\text { back pain? A screening } \\
\text { questionnaire for predicting } \\
\text { outcome in acute and subacute } \\
\text { back pain. }\end{array}$ & $\begin{array}{l}\text { Linton S.J. et al } \\
1998\end{array}$ & $\begin{array}{l}\text { Determinate the value of } \\
\text { psychosocial variables } \\
\text { in evaluating risk for } \\
\text { developing chronic back } \\
\text { pain problems. }\end{array}$ & $D=6 I=24$ \\
\hline $\begin{array}{l}\text { Job Content Questionnaire } \\
\text { (JCQ) }\end{array}$ & $\begin{array}{l}\text { The Job Content Questionnaire } \\
\text { (JCQ): an instrument for } \\
\text { internationally comparative } \\
\text { assessments of psychosocial } \\
\text { job characteristics. }\end{array}$ & $\begin{array}{l}\text { Karasek R. et al } \\
1998\end{array}$ & $\begin{array}{l}\text { Measurement of social } \\
\text { and psychological } \\
\text { characteristics of jobs. }\end{array}$ & $D=8 I=41$ \\
\hline $\begin{array}{l}\text { Copenhagen Psychosocial } \\
\text { Questionnaire (COPSOQ) }\end{array}$ & $\begin{array}{l}\text { A new tool for assessing } \\
\text { psychosocial factors at work: } \\
\text { the Copenhagen Psychosocial } \\
\text { Questionnaire }\end{array}$ & $\begin{array}{l}\text { Kristensen T.S. et } \\
\text { al } 2000\end{array}$ & $\begin{array}{l}\text { Assessment of psychosocial } \\
\text { factors at work, stress, well- } \\
\text { being and personality factor } \\
\text { of employees. }\end{array}$ & $\begin{array}{l}\text { Long version } D=30 \text {, } \\
I=141 \text {. Medium } \\
\text { version } D=26, I=95 \text {. } \\
\text { Short version } D=8 \text {, } \\
I=44 \text {. }\end{array}$ \\
\hline $\begin{array}{l}\text { General Questionnaire for } \\
\text { Psychological and Social } \\
\text { Factors at Work (QPS- } \\
\text { Nordic) }\end{array}$ & $\begin{array}{l}\text { Validation of the general Nordic } \\
\text { questionnaire (QPS-Nordic) for } \\
\text { psychological and social factors } \\
\text { at work }\end{array}$ & $\begin{array}{l}\text { Dallner M et al } \\
2000\end{array}$ & $\begin{array}{l}\text { Provide an indicator of } \\
\text { social and mental health in } \\
\text { work environment }\end{array}$ & $D=14 I=129$ \\
\hline $\begin{array}{l}\text { Dutch Musculoskeletal } \\
\text { Questionnaire (DMQ) }\end{array}$ & $\begin{array}{l}\text { Dutch Musculoskeletal } \\
\text { Questionnaire: description and } \\
\text { basic qualities }\end{array}$ & $\begin{array}{l}\text { Hildebrandt VH et } \\
\text { al. } 2001\end{array}$ & $\begin{array}{l}\text { Assessment of } \\
\text { musculoskeletal } \\
\text { workload and associated } \\
\text { potential hazardous } \\
\text { working conditions or } \\
\text { musculoskeletal symptoms } \\
\text { in worker populations. }\end{array}$ & $D=7 I=63$ \\
\hline $\begin{array}{l}\text { Tampa Scale for } \\
\text { Kinesiophobia (TSK) }\end{array}$ & $\begin{array}{l}\text { Fear of movement and (re)injury } \\
\text { in chronic musculoskeletal pain: } \\
\text { Evidence for an invariant two- } \\
\text { factor model of the Tampa Scale } \\
\text { for Kinesiophobia across pain } \\
\text { diagnoses and Dutch, Swedish } \\
\text { and Canadian samples. }\end{array}$ & $\begin{array}{l}\text { Roelofs J. et al } \\
2007\end{array}$ & $\begin{array}{l}\text { Measure of fear of } \\
\text { movement and (re)injury in } \\
\text { subject with work-related } \\
\text { musculoskeletal disease }\end{array}$ & $D=2 I=11$ \\
\hline
\end{tabular}

Studies' aims, fields of application and validation papers extracted through the literature review. The articles are listed in chronological order. The whole number of domains extracted through the literature review is 72 . Two or more questionnaires can investigate the same domain. The overall number of different domains is 38 . The overall number of different items is 504 .

reducing the prevalence of WMSDs and thereby also the burden. Countries that have implemented preventative strategies have seen a decreased prevalence of WMSDs compared with countries without or with less efficient strategies. ${ }^{24}$

The P4W consortium was formed to develop evidencebased educational materials, courses and tools for the prevention of WMSDs, which can be applied at individual, workplace and wider levels. Identification of the subjects and groups at higher risk is a requisite to increase the efficiency of preventive actions, and for this reason, the endeavour of developing and validating a short, selfadministered, multi-domain risk assessment questionnaire has been undertaken. 
Table 3 Final domain and items

\begin{tabular}{lll}
$\begin{array}{l}\text { Included } \\
\text { domain }\end{array}$ & Physical component & Psychosocial component \\
\hline 1 & $\begin{array}{l}\text { Quantitative work } \\
\text { demands } \\
\text { (COPSOQ) }\end{array}$ \\
2 & $\begin{array}{l}\text { Sensory work demands } \\
\text { (COPSOQ) }\end{array}$ \\
\hline
\end{tabular}

Items selected

a. Do you have to work very fast?

b. Is your workload unevenly distributed so it piles up?

c. How often do you not have time to complete all your work tasks?

a. Does your work demand a great deal of concentration?

b. Does your work demand your constant attention?

c. Does your work require a high level of precision?

$\begin{array}{ll}3 & \begin{array}{l}\text { Influence at work } \\ \text { (COPSOQ) }\end{array} \\ 4 & \begin{array}{l}\text { Possibilities for } \\ \text { development at work } \\ \text { (COPSOQ) }\end{array}\end{array}$

a. Do other people make decisions concerning your work?

b. Do you have a large degree of influence concerning your work?

c. Can you influence the amount of work assigned to you?

a. Do you have to do the same thing over and over again?

b. Can you use your skills or expertise in your work?

c. Does your work give you the opportunity to develop your skills?

5

6

7

8

9

10
Degree of freedom at work a. Can you decide when to take a break? (COPSOQ)

Meaning of work (COPSOQ)

\section{Role conflicts at work} (COPSOQ)

\section{Social support at work (COPSOQ)} wish? colleague?

a. Is your work meaningful? work? to you to be unnecessary? some people but not by others? colleagues? b. Can you take holidays more or less when you

c. Can you leave your work to have a chat with a

b. Do you feel that the work you do is important?

c. Do you feel motivated and involved in your work?

a. Are contradictory demands placed on you at

b. Do you sometimes have to do things, which seem

c. Do you do things at work, which are accepted by

d. Do you sometimes have to do things, which ought to have been done in a different way?

a. How often do you get help and support from your

b. How often do you get help and support from your immediate superior?

c. How often is your immediate superior willing to listen to your work-related problems?

a. Do you work isolated from your colleagues?

b. Is it possible for you to talk to your colleagues while you are working?

Social relations at work (COPSOQ)

a. Is there a good atmosphere between you and your colleagues?

b. Is there good co-operation between the colleagues at work?

c. Do you feel part of a community at your place of work? 
Table 3 Continued

\section{Included domain

domain Physical component

11

12

13

15

16

17

18

19

23

\section{Psychosocial component Items selected}

Insecurity at work

(COPSOQ)

Are you worried about...

Job satisfaction (COPSOQ)

How pleased are you with...

a. ... becoming unemployed?

b. ... It being difficult for you to find another job if you become unemployed?

c. ... having to give up your job for health reasons?

a. ... your job as a whole, everything taken into consideration?

b. ... the people you work with?

c. ... your work prospects?

General health (COPSOQ) a. I seem to get sick a little easier than other people.

b. I am as healthy as anybody I know.

c. I expect my health to get worse.

d. I need to see doctor and take medicine on a regular basis. *

4 Mental health (COPSOQ)

How much of the time during

a. ... have you felt so down in the dumps that

the past 4 weeks... nothing could cheer you up?

b. ... have you been a very nervous person?

c. ... have you felt calm and peaceful?

$\begin{array}{ll}\text { Vitality } & \text { a. ... did you have a lot of energy? } \\ \text { (COPSOQ) } & \text { b. ... did you feel worn out? }\end{array}$

(COPSOQ) b. ... did you feel worn out?

How much of the time during c. ... did you feel tired?

the past 4 weeks...

16 Behavioural stress

(COPSOQ)

a. I have difficulty to relax or enjoy myself. *

b. I have not been able to stand dealing with other people.

c. I have found it difficult to be happy.

17 Somatic stress a. ... had stomach ache or stomach problems?

(COPSOQ) b. ... had a tight chest or chest pains?

How much of the time during c. ... had tension in various muscles?

the past 4 weeks have you... d. ... had difficulty to sleep? *

Cognitive stress

a. ... had problems concentrating?

(COPSOQ)

b. ... had difficulty with remembering?

How much of the time during c. ... had difficulty in taking decisions?

the past 4 weeks have you... d. ... found it difficult to think clearly?

20

21

19 Sense of coherence

(COPSOQ)

\section{Problem-focused coping (COPSOQ)}

\section{Kinesiophobia}

(TSK)

22

Catastrophising

(PCS) a. I believe I can cope with most situations in life.

b. I feel that what I do in my daily life is meaningful.

c. I do not feel that I am able to influence my future to any great extent.

a. Do you try to find out what you can do to solve the problem?

b. Do you do anything to solve the problem?

a. I am afraid that I might injure myself if I exercise.

b. Simply being careful that I do not make any unnecessary movements is the safest thing I can do to prevent my pain from worsening.

c. If I were to try to overcome it, my pain would increase.

a. I become afraid that the pain will get worse.

b. I feel I ca not go on.

c. It's terrible and I think it's never going to get any better.

a. ... lift heavy loads (more than $5 \mathrm{~kg}$ )?

b. ... pull or push heavy loads (more than $5 \mathrm{~kg}$ )?

c. ... lift with the load far from the body?

d. ... lift in an awkward posture? 


\begin{tabular}{|c|c|c|c|}
\hline $\begin{array}{l}\text { Included } \\
\text { domain }\end{array}$ & Physical component & Psychosocial component & Items selected \\
\hline 27 & $\begin{array}{l}\text { Ergonomic environment } \\
\text { (DMQ) } \\
\text { Do you in your work often } \\
\text { have to... }\end{array}$ & & $\begin{array}{l}\text { a. ... not enough room around you to perform your } \\
\text { work properly? } \\
\text { b. ... difficulty in exerting enough force because of } \\
\text { uncomfortable postures? } \\
\text { c. ... not enough room above you to perform your } \\
\text { work without bending? }\end{array}$ \\
\hline
\end{tabular}

Operationalisation table. Final domains and related final items are presented. Each domain has been attributed to either the physical or the psychosocial component of the Patient Reported Outcome Measures (PROMs).

*Items built from scratch for their unique characteristics.

Construct, construct/domain number; COPSOQ, Copenhagen Psychosocial Questionnaire; DMQ, Dutch Musculoskeletal Questionnaire; PCS,

Pain Catastrophising Scale; TSK, Tampa Scale for Kinesiophobia.

\section{Assessing the risk of WMSDs}

The expert group working as part of the Delphi panel initially agreed that the conceptual model underlying a risk assessment questionnaire should address both a physical and a psychosocial component of risk. This expert agreement is in line with the literature, which provides substantial evidence from longitudinal studies of the contribution of both a physical and a psychosocial components with regards to the risk of developing WMSDs. ${ }^{21}$ Furthermore, the psychosocial dimension has been shown to correlate with the prevalence of chronic musculoskeletal conditions. ${ }^{37} 38$

During the domain selection process, both physical and psychosocial dimensions were presented to Delphi panel via the 38 potential domains identified through the literature search, of these domains, 6 were related to the physical dimension and 32 were with the psychosocial dimension. The work of the panel resulted in 28 domains and 89 items that provide a framework to operationalise the underlying domain constructs. All but four of the final items were from previous self-administered validated questionnaires. This increases the strength of the results in two ways. First, the underlying concepts are in agreement with the results of the last decades of research in occupational and musculoskeletal health; second, the robustness of the $\mathrm{P} 4 \mathrm{Wq}$ is expected to be high as the final product uses items from previous validated questionnaires. This approach has previously proven valid in the creation of simplified assessment tools in back disorders ${ }^{39} 40$

\section{Methodological considerations and limitations}

The different phases in the development of this questionnaire from definition of the construct to the list of items creation follow the international recommendations. ${ }^{4142}$ 
A well-accepted framework, the theory of biopsychosocial nature of musculoskeletal problems and the fear-avoidance model of chronic pain ${ }^{41}$ provides a solid conceptual framework for the assessment of the risk of developing chronic musculoskeletal pain and has undergone extensive research. The target population for the questionnaire (working adult individuals) and the concept that will be measured (risk of development of WMSDs) have been defined, and the measurement model is reported in accordance with the items included in the pool.

This study has some limitations. The factors associated with the risk of developing WMSDs and the factors associated with the risk of WMSDs evolution into chronicity are not necessarily the same. During this step of the framework construction process, the research was performed to be as inclusive as possible. Further studies will establish which factors have the most significant predictive capabilities for new diagnosis or evolution into chronicity. The Delphi panel included experts with different backgrounds regarding research and professional experience and was multidisciplinary. Still, one category of professionals (physical therapists) was overrepresented. Employers, members of the compensation system (society safety net and healthcare management) and stakeholders were not involved in the Delphi panel. This approach can potentially limit the infield application of the knowledge acquired. ${ }^{9}$ In particular, the workers' absence might cause limitations in terms of comprehensiveness of the items used. This limitation will be addressed in the validation phases by interviews, in which interviewees will be specifically asked about comprehensiveness.

\section{CONCLUSIONS}

No specific risk assessment questionnaires for WMSDs are currently available. The risk of developing WMSDs, which may potentially progress into chronic symptoms, is likely to be captured by an assessment tool that reflects both physical and psychosocial domains that include factors of the biopsychosocial model of disease and the fearavoidance components of chronic pain. The present study provides a definition of the measurement construct and operationalises it into domains and items that will permit the development and validation of the questionnaire.

\section{Author affiliations}

${ }^{1}$ IRCCS Istituto Ortopedico Galeazzi, Milano, Italy

${ }^{2}$ Department of Health Science and Technology, Aalborg University, Aalborg, Denmark

${ }^{3}$ Department of Physiotherapy, University College of Northern Denmark, Aalborg, Denmark

${ }^{4}$ Department of Physiotherapy, Faculty of Health Sciences, Universidad San Jorge, 50830 Villanueva de Gállego, Zaragoza, Spain

${ }^{5}$ Department of Clinical Medicine, Health, Aarhus University, Aarhus, Denmark ${ }^{6}$ Department of Occupational Medicine, University Research Clinic, Danish Ramazzini Centre, Regional Hospital Gødstrup, Herning, Denmark

${ }^{7}$ School of Health and Rehabilitation Sciences, The University of Queensland,

Brisbane, QLD, Australia

${ }^{8}$ School of Medical \& Health Sciences, Tung Wah College, Hong Kong SAR, China
${ }^{9}$ IRCCS Fondazione Don Carlo Gnocchi, Milano, Italy

${ }^{10}$ Department of Physiatry and Nursing, Faculty of Health Sciences, University of Zaragoza, Zaragoza, Aragón, Spain

Twitter Steffan Wittrup McPhee Christensen @SW_Christensen and Thorvaldur Skuli Palsson @tspalsson

Acknowledgements We thank Prof. Steven J. Linton (SJL) from Örebro University (Sweden) and Dr. Morten Villumsen (MV) from Aalborg University (Denmark) for their participation as scientific advisors for the study and external expert in the survey process.

Collaborators S J Linton (SJL); M Villumsen (MV).

Contributors All authors contributed significantly to the design of this study and lived up to the requirements of the International Committee of Medical Journal Editors (ICMJE). Author contribution varied in the different phases of the project with $\mathrm{FL}$ and PeBe being involved in all phases. PeBe, FL, PH, PB-L, TSP and JHV contributed to the conception, design and planning of the study. FL, PeBe, JHV, PH, PB-L, VD-G, MH, TSP, SWMC were enrolled as expert and MDC, VJ, GS, DC contributed as external expert in the Delphi group. FL and NG contributed to the data collection, and FL, PeBe and JHV were responsible for data analysis. The interpretation of data and writing of manuscript were led by PeBe, FL and PH with support from PB-L, TSP, MH, SWMC, VJ GS and DC. No patients were involved in this work.

Funding This study was funded by Erasmus+ Program (agreement number 20182381/001-001, project number 600920-EPP-1-2018-1-ES-EPPKA2-KA) and Italian Ministry of Health (agreement number not applicable).

Competing interests None declared.

Patient and public involvement Patients and/or the public were not involved in the design, or conduct, or reporting, or dissemination plans of this research.

Patient consent for publication Not required.

Provenance and peer review Not commissioned; externally peer reviewed.

Data availability statement Data can be made available on reasonable request to the authors.

Open access This is an open access article distributed in accordance with the Creative Commons Attribution Non Commercial (CC BY-NC 4.0) license, which permits others to distribute, remix, adapt, build upon this work non-commercially, and license their derivative works on different terms, provided the original work is properly cited, appropriate credit is given, any changes made indicated, and the use is non-commercial. See: http://creativecommons.org/licenses/by-nc/4.0/.

ORCID iDs

Francesco Langella http://orcid.org/0000-0002-8639-8480

Thorvaldur Skuli Palsson http://orcid.org/0000-0002-4418-0133

Pablo Bellosta-López http://orcid.org/0000-0003-4750-9077

Jorge Hugo Villafañe http://orcid.org/0000-0002-3239-7626

Pablo Herrero http://orcid.org/0000-0002-9201-0120

\section{REFERENCES}

1 Barbe MF, Barr AE. Inflammation and the pathophysiology of work-related musculoskeletal disorders. Brain Behav Immun 2006;20:423-9.

2 Parent-Thirion A, Biletta I, Cabrita J. Sixth European Working Conditions Survey - Overview report. Eurofound - Update 2019, 2017. Available: https://www.eurofound.europa.eu/publications/ report/2016/working-conditions/sixth-european-working-conditionssurvey-overview-report

3 Palsson TS, Boudreau S, Høgh M, et al. Education as a strategy for managing occupational-related musculoskeletal pain: a scoping review. BMJ Open 2020;10:e032668-8.

4 de Kok J, Vroonhof P, Snijders J. Work-Related musculoskeletal disorders: prevalence, costs and demographics in the EU European risk Observatory report. Luxemb Publ Off Eur Union 2019.

5 The U.S. Bureau of Labor Statistics. Nonfatal occupational injuries and illnesses requiring days away from work, 2020. Available: https:// www.bls.gov/news.release/osh2.nr0.htm

6 European Agency for Safety and Health at Work (EU-OSHA). WorkRelated musculoskeletal disorders - facts and figures. Synthesis report (of 10 national reports, 2020. 
7 Jackson T, Thomas S, Stabile V, et al. A systematic review and metaanalysis of the global burden of chronic pain without clear etiology in low- and middle-income countries: trends in heterogeneous data and a proposal for new assessment methods. Anesth Analg 2016;123:739-48.

8 Irastorza X, Milczarek M, Cockburn W. Second European survey of Enterprises on new and emerging risks (ESENER-2) overview report: managing safety and health at work European risk Observatory 2016.

9 Loisel P, Buchbinder R, Hazard R, et al. Prevention of work disability due to musculoskeletal disorders: the challenge of implementing evidence. J Occup Rehabil 2005;15:507-24.

10 Rosenberg NR, Petersen SB, Begtrup LM, et al. Early occupational intervention for people with low back pain in physically Demanding jobs: 1-year follow-up results of the randomized controlled GOBACK trial. Spine 2021;46:347-55.

11 Kristman VL, Lowey J, Fraser L, et al. A multi-faceted community intervention is associated with knowledge and standards of workplace mental health: the superior mental wellness @ work study. BMC Public Health 2019;19:638.

12 Kristman VL, Shaw WS, Boot CRL, et al. Researching complex and multi-level workplace factors affecting disability and prolonged sickness absence. J Occup Rehabil 2016;26:399-416.

13 Antcliff D, Keeley P, Campbell M, et al. The development of an activity pacing questionnaire for chronic pain and/or fatigue: a Delphi technique. Physiotherapy 2013:99:241-6.

14 Herdman M, Rajmil L, Ravens-Sieberer U, et al. Expert consensus in the development of a European health-related quality of life measure for children and adolescents: a Delphi study. Acta Paediatr 2002;91:1385-90.

15 Rutjes AWS, Reitsma JB, Coomarasamy A, et al. Evaluation of diagnostic tests when there is no gold standard. A review of methods. Health Technol Assess 2007;11:iii-ix. 51.

16 Tognetto A, Michelazzo MB, Ricciardi W, et al. Core competencies in genetics for healthcare professionals: results from a literature review and a Delphi method. BMC Med Educ 2019;19:1-10.

17 Slade SC, Dionne CE, Underwood M, et al. Standardised method for reporting exercise programmes: protocol for a modified Delphi study. BMJ Open 2014;4:e006682.

18 Ogrinc G, Davies L, Goodman D, et al. Squire 2.0 (standards for quality improvement reporting excellence): revised publication guidelines from a detailed consensus process. BMJ Qual Saf 2016;25:986-92.

19 Das D, Kumar A, Sharma M. A systematic review of work-related musculoskeletal disorders among handicraft workers. Int J Occup Saf Ergon 2020;26:55-70.

20 Ahn G, Hur S, Jung M-C. Bayesian network model to diagnose WMSDs with working characteristics. Int J Occup Saf Ergon 2020;26:336-47.

21 da Costa BR, Vieira ER. Risk factors for work-related musculoskeletal disorders: a systematic review of recent longitudinal studies. Am J Ind Med 2010;53:285-323.

22 Kraatz S, Lang J, Kraus T, et al. The incremental effect of psychosocial workplace factors on the development of neck and shoulder disorders: a systematic review of longitudinal studies. Int Arch Occup Environ Health 2013;86:375-95.

23 Palmer KT, Smedley J. Work relatedness of chronic neck pain with physical findings--a systematic review. Scand J Work Environ Health 2007;33:165-91.

24 Waddell G. 1987 Volvo award in clinical sciences. A new clinical model for the treatment of low-back pain. Spine 1987;12:632-44.
25 Basakci Calik B, Yagci N, Oztop M, et al. Effects of risk factors related to computer use on musculoskeletal pain in office workers. Int J Occup Saf Ergon 2020:1-6.

26 Burgess RA, Thompson RT, Rollman GB. The effect of forearm posture on wrist flexion in computer workers with chronic upper extremity musculoskeletal disorders. BMC Musculoskelet Disord 2008;9:47.

27 Szeto GPY, Straker LM, O'Sullivan PB. Neck-shoulder muscle activity in general and task-specific resting postures of symptomatic computer users with chronic neck pain. Man Ther 2009;14:338-45.

28 Waddell G, Newton M, Henderson I, et al. A Fear-Avoidance beliefs questionnaire (FABQ) and the role of fear-avoidance beliefs in chronic low back pain and disability. Pain 1993;52:157-68.

29 Hildebrandt VH, Bongers PM, van Dijk FJ, et al. Dutch musculoskeletal questionnaire: description and basic qualities. Ergonomics 2001;44:1038-55.

30 Kuorinka I, Jonsson B, Kilbom A, et al. Standardised Nordic questionnaires for the analysis of musculoskeletal symptoms. Appl Ergon 1987;18:233-7.

31 Kristensen TS, Hannerz H, Høgh A, et al. The Copenhagen Psychosocial Questionnaire--a tool for the assessment and improvement of the psychosocial work environment. Scand J Work Environ Health 2005;31:438-49.

32 Wännström I, Peterson U, Asberg M, et al. Psychometric properties of scales in the general Nordic questionnaire for psychological and social factors at work (QPs): confirmatory factor analysis and prediction of certified long-term sickness absence. Scand J Psychol 2009;50:231-44.

33 Karasek R, Brisson C, Kawakami N, et al. The job content questionnaire (JCQ): an instrument for internationally comparative assessments of psychosocial job characteristics. J Occup Health Psychol 1998;3:322-55.

34 Siegrist J, Starke D, Chandola T, et al. The measurement of effortreward imbalance at work: European comparisons. Soc Sci Med 2004;58:1483-99.

35 Roelofs J, Sluiter JK, Frings-Dresen MHW, et al. Fear of movement and (re)injury in chronic musculoskeletal pain: Evidence for an invariant two-factor model of the Tampa Scale for Kinesiophobia across pain diagnoses and Dutch, Swedish, and Canadian samples. Pain 2007;131:181-90.

36 Sullivan MJL, Bishop SR, Pivik J. The pain Catastrophizing scale: development and validation. Psychol Assess 1995;7:524-32.

37 Ortego G, Villafañe JH, Doménech-García V, et al. Is there a relationship between psychological stress or anxiety and chronic nonspecific neck-arm pain in adults? A systematic review and metaanalysis. J Psychosom Res 2016;90:70-81.

38 Linton SJ, Boersma K. Early identification of patients at risk of developing a persistent back problem: the predictive validity of the Orebro musculoskeletal pain questionnaire. Clin J Pain 2003;19:80-6.

39 Ferrer M, Pellisé F, Escudero O, et al. Validation of a minimum outcome core set in the evaluation of patients with back pain. Spine 2006;31:1372-9. discussion 1380.

40 Deyo RA, Battie M, Beurskens AJ, et al. Outcome measures for low back pain research. A proposal for standardized use. Spine 1998;23:2003-13.

41 Terwee CB, Prinsen CAC, Chiarotto A, et al. COSMIN methodology for evaluating the content validity of patient-reported outcome measures: a Delphi study. Qual Life Res 2018;27:1159-70.

42 Prinsen CAC, Mokkink LB, Bouter LM, et al. COSMIN guideline for systematic reviews of patient-reported outcome measures. Qual Life Res 2018;27:1147-57. 